\title{
A reliable method for ageing of whiting (Merlangius merlangus) for use in stock assessment and management
}

\section{Ross, Stine Dalmann; Hüssy, Karin}

Published in:

Journal of Applied Ichthyology

Link to article, DOI:

10.1111/jai.12204

Publication date:

2013

Document Version

Peer reviewed version

Link back to DTU Orbit

Citation (APA):

Ross, S. D., \& Hüssy, K. (2013). A reliable method for ageing of whiting (Merlangius merlangus) for use in stock assessment and management. Journal of Applied Ichthyology, 29, 825-832. https://doi.org/10.1111/jai.12204

\section{General rights}

Copyright and moral rights for the publications made accessible in the public portal are retained by the authors and/or other copyright owners and it is a condition of accessing publications that users recognise and abide by the legal requirements associated with these rights.

- Users may download and print one copy of any publication from the public portal for the purpose of private study or research.

- You may not further distribute the material or use it for any profit-making activity or commercial gain

- You may freely distribute the URL identifying the publication in the public portal 
Journal of Applied Ichthyology (2013)

http://dx.doi.org/10.1111/jai.12204

(c) 2013 Blackwell Verlag $\mathrm{GmbH}$

DTU Aqua

National Institute of Aquatic Resources

\title{
A reliable method for ageing of whiting (Merlangius merlangus) for use in stock assessment and management
}

\author{
Stine D. Ross* and Karin Hüssy \\ Technical University of Denmark, National Institute for Aquatic Resources, Kavalergaarden 6, DK-2920 \\ Charlottenlund, Denmark
}

\begin{abstract}
Accurate age estimation is important for stock assessment and management. The importance of reliable ageing is emphasized by the impending analytical assessment of whiting (Merlangius merlangus) in the Baltic Sea. Whiting is a top predator in the Western Baltic Sea, and is fished commercially although less extensively compared to the North Sea. Even though the species is considered one of the most difficult gadoids to age, few efforts have been made to shed light on the ageing problems. The aim of the present study was to identify and validate the $1^{\text {st }}$ winter ring and to examine the visibility of the subsequent winter rings. Microstructure analysis was used to confirm the $1^{\text {st }}$ winter ring. Additionally, otolith growth trajectories were obtained, confirming the allometric growth seen in many fish species. The method for ageing of whole otoliths presented in this study can be directly implemented in future ageing of whiting otoliths from the Baltic Sea - and potentially also adjacent areas where the conspecifics have similar growth rates.
\end{abstract}

Keywords: age estimation, otolith growth, validation, microstructure analysis, assessment

*Corresponding author: sdro@aqua.dtu.dk

Article first published online: 10 APR 2013

Please note that this is an author-produced PostPrint of the final peer-review corrected article accepted for publication. The definitive publisher-authenticated version can be accesses here: http://dx.doi.org/10.1111/jai.12204 


\section{Introduction}

24 Whiting (Merlangius merlangus) is a commercially fished species throughout most of its

25 distribution range. The increasing importance of the species in the North Sea and the Skagerrak

26 is seen in the catches which have increased concomitantly with a decrease in catches of other

27 gadoids such as cod (Gadus morhua) and haddock (Melanogrammus aeglefinus) (Anon.

$282012 a / b$ ). In the current EU directive regarding sampling of commercially important species, it is

29 only obligatory to collect whiting in the North Sea, Kattegat and Skagerrak (EU 2010).

30 Analytical assessment is, currently, only conducted for whiting in the North Sea.

31 Acknowledging that whiting is a top predator in the western Baltic Sea, it is important to

32 investigate its role, i.e. life-history traits, ecology and population dynamics. Such information

33 can be used in multispecies modeling and for potential future analytical assessment. This

34 emphasizes the importance of correct age estimation since under- or overestimation will

35 influence ecological studies and bias the assessment (Beamish \& McFarlane 1983; Campana

36 2001; Reeves 2003; de Pontual et al. 2006). Whiting is considered to be a difficult gadoid to age

37 (CEFAS 2005), and it is therefore essential to develop a reliable ageing method, which has

38 potential application for other whiting stocks as well.

39 Vertebrae, scales, fin rays and otoliths are all used in ageing of fish, the latter being the primary method (Campana 2001; Campana \& Thorrold, 2001). Routine ageing of otoliths is based on

41 visual identification of growth zones (Campana \& Thorrold 2001); an opaque zone is formed

42 during the growth period (summer) and a translucent zone during periods of slow growth

43 (winter). An annulus comprises both zones, but as $1^{\text {st }}$ of January is set to be the birth date of all 
44 fish, only the translucent zones are counted when ageing (Pannella 1974; Smedstad \& Holm, 45 1996).

46 Though commonly used, the traditional age estimation method has proven to be quite

47 challenging in many gadoids such as Baltic cod (Hüssy 2010; Rehberg-Haas et al. 2012),

48 European hake (Morales-Nin et al. 1998; de Pontual et al. 2006) and whiting (Polat \& Gümüs

49 1996; CEFAS 2005). Validation is required to ensure correct and reliable ageing (Beamish \&

50 McFarlane 1983). The most appropriate method to validate the age of a fish species is by

51 mark/recapture studies marking both fish and otolith. This technique, however, is very time-

52 consuming (Beamish \& McFarlane 1983; Polat \& Gümüs 1996; Campana 2001). Methods for

53 identifying the $1^{\text {st }}$ winter ring and investigating the seasonality in ring pattern have been applied

54 such as breaking or grinding of otoliths (Polat \& Gümüs 1996), microstructure analysis (Hüssy

55 2010; Hüssy et al. 2010) or other methods (see review by Campana 2001).

56 The otoliths of whiting exhibit a similar annulus pattern as seen in many other fish species with a

57 broad opaque zone forming during the growth season (spring-summer) and a narrow translucent

58 zone during the period of reduced growth (winter) (Bowers 1954). As whiting grow larger,

59 calcium carbonate is accumulated in the area around the nucleus, inhibiting the visibility of the

$601^{\text {st }}$ and possibly also $2^{\text {nd }}$ winter ring. This has been observed in whiting in the North Sea

61 (Gambell \& Messtorff 1964), the Irish Sea (Bowers 1954) and the Black Sea (Polat \& Gümüs

62 1996). In the latter study it was concluded that due to the thickness of the central area of the

63 otolith, the risk of missing the $1^{\text {st }}$ and $2^{\text {nd }}$ annuli is high, hampering ageing based on whole

64 otoliths. Problems relating to false winter rings, i.e. translucent zones formed during the year in

65 response to changes in the environment, have additionally been reported for North Sea whiting

66 (CEFAS 2005). 
67 Different ageing methods such as grinding and breaking of the otoliths have been tested in

68 whiting from other areas. Grinding of otoliths is a reliable but time-consuming method (Bowers

69 1954; Gambell \& Messtorff 1964; Polat \& Gümüs 1996). Breaking of otoliths is a useful method

70 for ageing of younger whiting (Polat \& Gümüs 1996; CEFAS 2005), but as the fish grow older,

71 the ring pattern becomes increasingly difficult to distinguish due to decreasing distances between

72 the annuli (Gambell \& Messtorff 1964). These studies have primarily focused on finding the best

73 age estimation method, although investigating the seasonality in the edge formation is part of the

74 age validation process. The first step in the validation process is to identify and validate the $1^{\text {st }}$

75 winter ring (Campana 2001). The next step is to investigate the seasonality in the edge zone

76 formation and to explore the consistency of the annulus pattern (Campana 2001). Both steps

77 should theoretically be carried out for all age classes and for different years (Beamish \&

78 McFarlane 1983), though this is often difficult to achieve (Campana 2001).

79 Using whiting from the Western Baltic Sea, the objectives of this study are (1) to confirm the 80 previous findings on whiting otoliths, i.e. the increasing difficulties in distinguishing the first 81 annuli with increasing fish size and the seasonality in zone formation, (2) to identify and validate

82 the first annulus and (3) to show individual otolith growth profiles, which will shed light on the 83 changes in otolith growth rate from juvenile to adult. Additionally, a smaller sample of otoliths

84 from the North Sea was examined to investigate whether similar problems regarding the 85 decreasing visibility of the $1^{\text {st }}$ winter ring exist.

\section{Materials and Methods}

\section{Sample selection}


89 Whiting were caught randomly during the extended BITS surveys in November 2011, January

90 and May 2012. Stratified random sampling according to ICES square and depth stratification was

91 conducted in the Fehmarn Belt (with a standard TV3-520 bottom otter trawl, OTB) in the

92 southern part of the ICES subdivision 22 (fig. 1). The whiting were measured to the nearest $\mathrm{cm}$

93 below, weighed and the sagittal otoliths removed.

94 Fish used for identifying the $1^{\text {st }}$ annulus by microstructure analysis were selected randomly from

95 the peaks in the 2009, 2010 and 2011 cohort length distributions (i.e. 0-3 group), respectively

96 (fig. 2). A total of 60 fish were selected (20 fish per survey), covering a length range of $8-30 \mathrm{~cm}$.

97 Fish belonging to the 2009-2010 year-classes were subsequently used to test whether the

98 increment pattern in older fish was consistent with the patterns observed in the first year of the

99 same cohort. However, as year classes of whiting from other areas have been shown to overlap in

100 length ranges (Gambell \& Messtorff 1964; Flintegaard 1980; Armstrong et al. 2004), the tails of

101 each cohort's length distribution were also sampled. These fish were also used in the edge

102 formation analysis and for examining the visibility of the $1^{\text {st }}$ annulus. Additional 11 fish in the

103 size range $30-36 \mathrm{~cm}$ were included in the latter analysis to confirm that only the $1^{\text {st }}$ winter ring

104 "disappeared" in the larger fish.

105 No samples were available for the $3^{\text {rd }}$ quarter in the Fehmarn Belt surveys. To investigate the 106 seasonality in the otolith edge formation, additional samples were taken with midwater otter 107 trawl (OTM) in the acoustic survey performed by the German vessel, R/V Solea in September 1082011 in ICES subdivision 24 (fig. 1). 20 fish were randomly selected and otoliths from them only 109 used for the edge formation analysis. Together with otoliths used for the identification of the $1^{\text {st }}$ 110 annulus, otoliths from a total of 80 fish were used in the edge formation analysis. 
111 To test the applicability of this approach to other stocks, 15 otoliths from whiting in the North

112 Sea were used in a separate analysis. Fish were randomly selected from a discard survey

113 conducted with a multi-rig otter trawl (OTT, $90 \mathrm{~mm}$ mesh size) in June 2011 in the northeastern

114 part of the North Sea (close to the Skagerrak). These fish covered a length range of $17-28 \mathrm{~cm}$.

116 Analyses

117 Otoliths were investigated using three different methods: (1) ageing of whole otoliths, (2) ageing

118 of ground otoliths and (3) examination of daily increment patterns, i.e. detection of zones with

119 relatively smaller increments (low growth) assumed to correspond to the formation of a winter

120 ring. The analyses were based on the following assumptions: (1) one year's growth corresponds

121 to an opaque and a translucent zone; (2) this pattern is consistent throughout the life of the fish;

122 and (3) periods of slow and fast growth (i.e. during winter and summer) can be observed as

123 zones of decreasing and increasing daily increment widths. All image analyses were carried out

124 in IMAGE PRO (vs. 5.0) and for the statistical analyses the Statistical Software $R$ (R

125 Development Core Team, 2009) was used.

127 Ageing of whole otoliths

128 The otoliths were placed in propylene glycol, sulcus facing upwards, and viewed under a

129 stereomicroscope (Leica MZ12) at a $1.25 \mathrm{x}$ magnification corresponding to $2.56 \mu \mathrm{m}$ pixel $^{-1}$ using 130 reflected light in a standardized set-up. Images were digitized (Leica camera DFL290) using a 
131 standard set-up. The distance from the nucleus to the $1^{\text {st }}$ annulus $\left(\mathrm{D}_{\text {Traditional }}\right)$ was measured on the 132 anterior axis from the nucleus towards the tip of the rostrum (fig. 3).

\section{Ageing of ground otoliths}

135 The otoliths were glued to a glass slide using thermoplastic resin (Buehler) and ground on both 136 sides on a rotating disc with two different abrasive papers (grit $3 \mu \mathrm{m}$ and grit $1200 \mu \mathrm{m}$ ) to a 137 thickness of approximately $500 \mu \mathrm{m}$. The ground otoliths were viewed and treated according to 138 the procedure above. The distance from the nucleus to the $1^{\text {st }}$ annulus $\left(D_{\text {Ground }}\right)$ was measured 139 (fig. 3).

141 Annulus pattern and individual growth trajectories

142 The consistency of the sequential annuli was investigated and it was further tested whether there 143 was a correlation between the $1^{\text {st }}$ visible annulus in the whole otoliths and the $2^{\text {nd }}$ annulus in the 144 ground otoliths. This was done by comparing the distance from the nucleus to the $1^{\text {st }}$ winter ring $145\left(\mathrm{D}_{\text {Traditional }}\right)$ in the whole otoliths with the distance from the nucleus to the $2^{\text {nd }}$ winter ring

$146\left(\mathrm{D}_{2 \text { Ground }}\right)$ in the ground otoliths. Similarly, the $2^{\text {nd }}$ visible annulus in the whole otoliths was 147 compared with the $3^{\text {rd }}$ annulus in the ground otoliths 
150 Microstructure analysis of the daily increments generates a similar pattern as the yearly banding

151 with translucent zones corresponding to the period of slow growth (usually during the night) and

152 opaque zones corresponding to the period of fast growth (day). One increment is comprised of a

153 translucent and an opaque zone. Microstructure analysis or marginal increment analysis (MIA) is

154 a good method to identify and validate the $1^{\text {st }}$ winter ring (Campana 2001). Increment widths

155 should display a sinusoidal cycle when plotted against time, i.e. during winter the widths

156 decrease and during summer they increase (Campana 2001).

157 The ground otolith sections were viewed under a microscope (Leica DMLB) at a 10x

158 magnification corresponding to $0.46 \mu \mathrm{m} \mathrm{pixel}^{-1}$ using reflected light in a standardized set-up.

159 Images were digitized (QImaging QIcam Fast 1394) using a standard set-up. The daily growth

160 increments were investigated using the "caliper tool" in IMAGE PRO (vs. 5.0) which generates a

161 profile of grey values ranging between 0 , black, and 255, pure white. The beginning of an

162 increment was defined as the rising point of inflection between the previous opaque zone and the

163 subsequent translucent zone and was calculated from the divergence of individual pixel grey

164 values from the running average. The distance from the nucleus on progressing days $i$ was

165 calculated as Distance $_{i}=$ Distance $_{i-1}+$ Increment $_{i}$. The Distance Di- $_{1}$ was standardized to the

166 anterior axis by multiplying with the ratio between the length of the anterior axis and the length

167 of the axis used for increment measurements. The Increment ${ }_{i}$ was standardized in a similar way,

168 i.e. by multiplying with the ratio between the increment widths on the anterior axis and the

169 increment widths on the axis used for increment measurements. Zones in which increments were

170 difficult to distinguish were measured and added to the total distance, but leaving out the

171 individual increments from the analysis. To reduce the inter-individual variation, the increment

172 widths for each individual were standardized to the widest increment (increment ${ }_{i} /$ increment $_{\text {max }}$ ). 
173 This resulted in growth profiles (nucleus to edge) showing the increment widths in relation to the

174 distance from the nucleus. The distance from the nucleus to the midpoint of the $1^{\text {st }}$ zone with

175 decreasing increment widths, $\mathrm{D}_{\text {Increment, was measured. }}$

176

177 Seasonal otolith edge formation

178 The otolith edge was investigated to determine when the formation of the winter ring is initiated

179 and ended. Four months were chosen (January, May, September and November) and 20-30

180 otoliths were analyzed per month. The otoliths were ground in accordance with the procedure

181 mentioned above and the edge of each otolith was inspected visually. Otoliths were categorized

182 as having an opaque or translucent edge, respectively.

184 North Sea otoliths

185 Ageing of whole and ground otoliths from the North Sea was conducted in a similar way as with 186 the Baltic Sea otoliths. Only otoliths of fish above $16 \mathrm{~cm}$ were included in this analysis as

187 problems regarding the visibility of the $1^{\text {st }}$ winter ring do not arise until the fish reach a certain 188 size (Bowers 1954; Gambell \& Messtorff 1964; Polat \& Gümüs 1996).

\section{Results}

191 Comparison of $\mathbf{D}_{\text {Traditional }}$ and $\mathbf{D}_{\text {Ground }}$ 
192 The central area of the whiting otolith is thick and the zones less distinctive (fig. 4a).

193 Comparison of whole and ground otoliths showed that the first annulus becomes increasingly

194 difficult to detect by traditional ageing of whole otoliths as the fish grow larger (fig. 4a). There

195 was a significant difference between the values of the ageing of the whole otoliths and the 196 ground otoliths (paired t-test, $\mathrm{df}=70, \mathrm{p}<0.001$ ). This is also seen when comparing the actual

197 distances from nucleus to $1^{\text {st }}$ annulus, $\mathrm{D}_{\text {Traditional }}$ and $\mathrm{D}_{\text {Ground }}$ (paired t-test, $\mathrm{df}=68, \mathrm{p}<0.05$ ).

198 The distance from nucleus to $1^{\text {st }}$ annulus increases linearly with fish size up until a size of $16 \mathrm{~cm}$

199 in both whole and ground otoliths (fig. 5a). Thus, $\mathrm{D}_{\text {Traditional }}$ and $\mathrm{D}_{\text {Ground }}$ are not significantly

200 different in fish $<17 \mathrm{~cm}$ (ANOVA, df $=65, \mathrm{p}=0.523)$. At fish lengths $\geq 17 \mathrm{~cm}, \mathrm{D}_{\text {Traditional }}$

201 continues to increase linearly with fish length, whereas $\mathrm{D}_{\text {Ground }}$ stops at a threshold value of

202 approximately $3600 \mu \mathrm{m}$. This gives an interval of $1800 \mu \mathrm{m}(\sim 1800-3600 \mu \mathrm{m})$ from the nucleus in 203 which the $1^{\text {st }}$ winter ring can be assumed to lie within.

205 Comparison of $\mathbf{D}_{\text {Traditional }}$ and $\mathbf{D}_{\mathbf{2} \text { Ground }}$

206 The $2^{\text {nd }}$ annulus was not difficult to distinguish in the whole otoliths investigated in this study,

207 i.e. the $1^{\text {st }}$ visible translucent zone observed in the whole otoliths in the $2+$ groups corresponded

208 well with the $2^{\text {nd }}$ translucent zone seen in the otoliths after grinding (ANOVA, df $=41, p=$

209 0.579) (fig. 5b). Similarly when comparing the distance from the nucleus to the $3^{\text {rd }}$ annulus in the

210 ground otoliths with the distance from the nucleus to the $2^{\text {nd }}$ annulus in the whole otoliths

211 (ANOVA, df $=41, \mathrm{p}=0.860)$ and for the $4^{\text {th }}$ annuli $($ ANOVA, $d f=17, p=0.823)$. 


\section{Comparison of $\mathbf{D}_{\mathrm{Ground}}$ and $\mathbf{D}_{\text {Increment }}$}

214 The daily increment widths generated a dome-shaped pattern with increasing widths during

215 summer, where the fish grows, and decreasing widths during winter, when growth is stalled (fig.

216 6a). The increment widths become very narrow, but they never disappear completely (fig. 6b).

217 By applying a fifth degree polynomial trend line to each growth profile, the midpoint of the area

218 of consistently decreasing increment widths was identified visually and the distance from

219 nucleus to the midpoint $\left(\mathrm{D}_{\text {Increment }}\right)$ was recorded. This area corresponded well with the formation

220 of a translucent zone (fig. 6c). Additionally, there appears to be a juvenile/settling zone

221 approximately $1500 \mu \mathrm{m}$ from the nucleus, which should not be misinterpreted as the first winter

222 ring (fig. 4b). This was confirmed by the microstructure analysis which showed continuously

223 broad increment widths throughout the zone. A winter ring would have corresponded with a

224 decrease in increment width. Based on the microstructure analysis, an interval for each winter

225 ring could be obtained (table 1). The juvenile zone was only visible in the ground otoliths and it

226 was narrower than the winter rings.

227 There was a high degree of consistency between $\mathrm{D}_{\text {Ground }}$ and $\mathrm{D}_{\text {Increment }}(\mathrm{ANOVA}, \mathrm{df}=67, \mathrm{p}=$ 228 0.905) (fig. 6a/c). Combining the two methods provides an estimate of the maximum distance 229 from the nucleus to the $1^{\text {st }}$ annulus, which was found to be $3600 \mu \mathrm{m}$.

\section{Growth trajectories}

232 The otoliths from the larger fish all showed a consistent winter ring pattern with decreasing

233 distances between the annuli (fig. 7, table 1). The range of each winter ring was large, indicating 
234 that significant variation in otolith growth exists (table 1). Additionally, the ranges overlapped,

235 i.e. the upper limit for the $1^{\text {st }}$ annulus was $\sim 3600 \mu \mathrm{m}$ and the lower limit for the $2^{\text {nd }}$ annulus was

$236 \sim 2900 \mu \mathrm{m}$ (table 1, fig. 5).

\section{Seasonal otolith edge formation}

239 The development in the opacity of the edge zone followed a seasonal pattern, although

240 differences between otoliths existed. It was difficult to determine the degree of opacity of

241 otoliths sampled in May and November as these months are part of a transition period in which

242 the growth is either increased or reduced. Optical effects as well as the thermoplastic resin, in

243 which the otoliths lay in, further complicated the interpretation. Most of the otoliths analyzed in

244 January were observed to have a translucent edge, whereas in May approximately $30 \%$ had a

245 translucent zone (fig. 8). In September, only a very small fraction had a translucent zone and this

246 fraction increased in November to approximately $70 \%$ (fig. 8).

\section{$248 \quad$ North Sea otoliths}

249 Comparison of whole and ground otoliths did not show a similar consistent problem in relation

250 to distinguishing the $1^{\text {st }}$ winter ring (paired t-test, $\mathrm{df}=14, \mathrm{p}=0.334$ ). The distance between the

251 nucleus and the $1^{\text {st }}$ annulus was not significantly different (paired t-test, $\mathrm{df}=14, \mathrm{p}=0.216$ ).

252 Nevertheless, the opaque zones were difficult to distinguish in two out of the fifteen otoliths, and

253 grinding was necessary to ensure that the ageing was correct. 


\section{Discussion}

256 This study confirmed earlier studies which have shown that traditional ageing of whiting otoliths

257 is challenging and may result in underestimation of age (Gambell \& Messtorff 1964; Polat \&

258 Gümüs 1996). In order to validate the winter ring formation, three issues were addressed: (1)

259 seasonality of the otolith edge formation, (2) identification of the $1^{\text {st }}$ winter ring and examination

260 of the visibility of the $2^{\text {nd }}$ and succeeding winter rings, and (3) individual otolith growth

261 trajectories. Additionally, otoliths from North Sea whiting were examined to test the applicability

262 of the present approach to other stocks.

263 Beamish \& McFarlane (1983) were very strict about the validation of all ages and stated that

264 extrapolation beyond the maximum validated age between populations can result in serious

265 errors. They also pointed out that the only correct validation method is by mark/recapture.

266 Considering the temporal scale of such a validation study as well as the fact that a large amount

267 of the tagged fish would end up in the fishing nets during the first few years, the approach

268 presented in this study is a valid substitute. The difficulties of obtaining whiting with known ages

269 were also stressed by CEFAS (2005). With regard to validation of all ages, it was considered

270 reliable to focus on identifying the $1^{\text {st }}$ winter ring as the main issue in whiting appears to be the

271 increasing thickness of the core area of the otolith with age, inhibiting the visibility of the $1^{\text {st }}$

272 winter ring in whole otoliths (Bowers 1954; Gambell \& Messtorff 1964; Polat \& Gümüs 1996).

273 This conclusion was supported in the present study which showed that from the $2^{\text {nd }}$ winter ring

274 and onwards, the annuli were always visible.

275 In accordance with earlier studies (Bowers 1954; Gambell \& Messtorff 1964), the edge

276 formation was found to vary over the seasons with most otoliths having a translucent edge in the 
277 winter and early spring. Thus, one of the main requirements put forth in the beginning of the

278 study is fulfilled, i.e. the synchronous appearance across all individuals of an opaque and a

279 translucent zone corresponding to fast and slow growth, respectively.

280 The microstructure analysis showed a consistent pattern with increasing increment widths in the

281 period corresponding to summer, where the temperatures are high, and decreasing increment

282 widths during winter (fig. 6a). This pattern persisted in the $2^{\text {nd }}$ and $3^{\text {rd }}$ year of life in the otoliths

283 studied, and is thus considered to be representative for all year-classes. The observed increment

284 pattern is seen in other gadoids like Baltic cod (Hüssy 2010; Hüssy et al. 2010), haddock and

285 saithe (Quiñonez-Velázquez 1998), but also in other fish species, e.g. Atlantic herring (Clausen

286 2006; Oeberst et al. 2006), boarfish (Hüssy et al. 2012), and sprat (Baumann et al. 2006).

287 The increment widths became successively narrower during winter, but never ceased completely 288 as in eastern Baltic cod (Hüssy 2010; Hüssy et al. 2010), North Sea herring (Clausen 2006) and

289 boarfish (Hüssy et al. 2012), where the increments disappear during winter concurrently with the

290 formation of the translucent zone. The reason for the continuous increment formation in Baltic

291 Sea whiting is not known and analyses of the increment pattern in older fish as well as in whiting

292 from adjacent areas should be conducted to investigate this further.

293 The $1^{\text {st }}$ annulus was identified in 0 to 3-group fish by applying microstructure analysis which

294 confirmed the first translucent zone to be a winter ring associated with low water temperatures.

295 In some of the otoliths a translucent zone approximately $1500 \mu \mathrm{m}$ from the nucleus was

296 observed. Though the zone appeared translucent, no concurrent decrease in increment widths

297 was observed, and the zone was thus not considered to be an annulus. This juvenile/settling zone

298 may be similar to the one found in whiting from the Irish Sea and the North Sea, referred to as 
299 the Bowers' zone, which is formed during late summer and likely relates to the change from 300 pelagic to demersal habitat (Bowers 1954; Gambell \& Messtorff 1964). It was generally easy to 301 distinguish from the translucent zone formed during the first winter as the juvenile zone appeared 302 close to the nucleus $(\sim 1500 \mu \mathrm{m})$. Bowers (1954) also noted that the translucent zone is much 303 narrower than the actual annulus and this was also confirmed in the present study. More 304 importantly, the microstructure analysis confirmed that this zone was not a winter ring since no 305 decrease in increment widths was observed. The juvenile zone is only visible in ground otoliths, 306 where microstructure analysis may reveal its nature.

307 The distance from the nucleus to the $1^{\text {st }}$ winter ring showed large variation, the same applied to 308 the succeeding winter rings (table 1). Whiting is a batch spawner, and in the North Sea and the 309 Irish Sea, the species have been reported to spawn over an extended period (February to 310 September) (Bowers 1954; Gambell \& Messtorff 1964; Hislop 1975; Cohen et al. 1991), hence it 311 does not seem unreasonable to have a large variation in otolith growth, i.e. larvae hatched late in 312 the season will have a significantly reduced growth season. The 1-group fish (2011 cohort) used 313 in this study ranged in size from $8-20 \mathrm{~cm}$ with the smallest fish being caught in May.

314 Whiting from the present study were capable of growing up to $20 \mathrm{~cm}$ within the first year of life.

315 The rapid growth was also confirmed by the otolith growth trajectories which showed large 316 otolith growth during the first year and then decreasing growth in the succeeding years (fig. 7).

317 Bowers (1954) noted that from the second year and onwards, the growth is more moderate, i.e. 5$3186 \mathrm{~cm}$ per year in Irish Sea whiting.

319 In most marine fish species, the initial growth is determining for growth later in life, hence a fish 320 with a low growth rate in the first year will usually have slow growth throughout its life span 
321 (Krohn \& Kerr 1997; Armstrong et al. 2004; Rindorf 2008). This was also seen in the present

322 study, where fish with the largest initial otolith growth generally achieved the overall largest

323 otolith growth (fig. 7), corresponding to the highest length-at-age. The decrease in otolith growth

324 with age is in agreement with the allometric growth seen in most species, especially after

325 maturation where a proportion of the energy is allocated towards reproduction (Björnsson \&

326 Steinarsson 2002).

327 The fact that the ranges of the winter rings overlapped (table 1) was not surprising considering

328 the large variation in hatching time and the resulting overlap in length distributions for the

329 different year-classes. The large variation in length-at-age is also seen in whiting from other

330 areas (Bowers 1954; Gambell \& Messtorff 1964; Flintegaard 1980; Armstrong et al. 2004;

331 CEFAS 2005). Similar overlap in the ranges of the winter rings are reported in Baltic cod (Hüssy 332 2010).

334 Manual to ageing of whiting

335 The otoliths showed a consistent winter ring pattern with decreasing distances between the 336 annuli like in otoliths from Irish Sea and North Sea whiting (Bowers 1954; Gambell \& Messtorff 337 1964) as well as in other gadoids such as hake (Morales-Nin et al. 1998) and Baltic cod (Hüssy 338 2010; Hüssy et al. 2010).

339 CEFAS (2005) provided guidelines for the ageing of North Sea whiting. It was generally 340 recommended to break or section the otoliths, but if read whole the rostrum (i.e. the pointed part 341 of the otolith) is considered the most reliable part of the otolith. In the present study, the post342 rostrum or the anterior side of the otolith was found most suitable for ageing of both whole and 
343 ground otoliths, as the winter rings were generally difficult to distinguish in the rostrum or the

344 posterior side (fig. 3). Sectioning of the otoliths is not considered the most appropriate method

345 for ageing of whiting as the annuli in older fish become very narrow and may be difficult to

346 distinguish (Gambell \& Messtorff 1964), especially in Baltic Sea whiting. Therefore grinding of

347 otoliths is the preferred method. The present study enables reliable ageing of whole otoliths by

348 following the guidelines below.

349 Based on the results from this study, guidelines for ageing routines of whiting were established:

350 - Preparation (propylene glycol for $15 \mathrm{~min}$ or distilled water for 24 hours to enhance the

$351 \quad$ visibility of the opaque zones)

352 - Identify visible translucent zones

353 - Determine whether the edge is opaque or translucent

354 - Consult the catch date. If the fish was captured

355

1) Before January $1^{\text {st }}$, the translucent edge is not counted

356

2) After January $1^{\text {st }}$, the translucent edge is included in the count

- Measure the distance from the nucleus to the $1^{\text {st }}$ visible translucent zone

1) If $1500-3400 \mu \mathrm{m}$, the translucent zone can be considered as the $1^{\text {st }}$ winter ring

2) If close to $3600 \mu \mathrm{m}$, check the otolith growth trajectory, i.e. measure and compare the distances between the winter rings (c.f. fig. 7 and table 1)

3) If $>3600 \mu \mathrm{m}$, the $1^{\text {st }}$ annulus is likely hidden rise to either (2) or (3), grinding or sectioning of the otolith must be performed. 


\section{Future perspectives}

366 The method developed in the present study likely applies to whiting from other areas as well,

367 although the crosscheck, i.e. the maximum distance from the nucleus to the $1^{\text {st }}$ winter ring, may

368 differ somewhat between areas. In this study, a smaller amount of otoliths from whiting

369 inhabiting the North Sea was examined and even though no apparent problem with

370 distinguishing the $1^{\text {st }}$ winter ring existed, some of the otoliths were thick which made it difficult

371 to distinguish all of the winter rings. Nevertheless, decreasing visibility of the $1^{\text {st }}$ annulus has

372 been reported for otoliths from whiting in the North Sea (Gambell \& Messtorff 1964), and

373 whether this only applies to some subpopulations inhabiting the area, is yet to be investigated.

374 This emphasizes the usage of the method developed in this study where grinding of the otolith is

375 employed whenever doubt arises. More thorough analyses of whiting otoliths from other areas

376 should be conducted to investigate whether similar or other problems regarding ageing of whole

377 otoliths exist.

378 The results obtained in this study, together with results from previous ones, emphasize the need

379 for a more holistic approach which incorporates length, catch date overall annulus pattern and 380 application of a crosscheck (maximum distance from the nucleus to the $1^{\text {st }}$ annulus). The

381 stepwise method presented here can be directly implemented in ageing of whole otoliths and

382 should provide correct age estimation, thereby ensuring the reliability and precision of analytical 383 assessment of whiting. 
386 The authors would like to thank the two reviewers for their suggested amendments which have 387 improved the manuscript. 


\section{References}

389

390

391

392

393

394

395

396
Anon. 2012a. Cod in subarea IV (North Sea) and divisions VIId (Eastern Channel) and IIIa West (Skagerrak). Advice June 2012. ICES Advice 2012, Book 6, section 6.4.2.

Anon. 2012b. Haddock in subarea IV (North Sea) and division and IIIa West (Skagerrak). Advice June 2012. ICES Advice 2012, Book 6, section 6.4.3.

Armstrong, M.J., Bromley, P., Schön, P.-J., \& Gerritsen, H.D. 2004. Changes in growth and maturity in expanding and declining stocks: evidence form haddock, cod and whiting populations in the Irish and Celtic Seas. ICES CM (K): 09.

Baumann, H., Hinrichsen, H.H., Voss, R., Stepputtis, D., Grygiel, W., Clausen, L.W. \& Temming, A. 2006. Linking growth to environmental histories in central Baltic young-of-theyear sprat, Sprattus sprattus: an approach based on otolith microstructure analysis and hydrodynamic modeling. Fish. Oceanogr. 15 (6): 465-76.

Beamish, R.J. \& McFarlane, G.A. 1983. The forgotten requirements for age validation in fisheries biology. T. Am. Soc. 112: 735-43.

Björnsson,B. and Steinarsson,A. 2002. The food-unlimited growth rate of Atlantic cod (Gadus morhua). Can. J. Fish. Aquat. Sci. 59: 494-502.

Bowers, A.B. 1954. Breeding and growth of whiting (Gadus merlangus L.) in Isle of Man waters. J. Mar. Biol. Ass., UK, 33: 97-122.

CEFAS 2005. Report of the whiting (Merlangius merlangus, L) otolith exchange scheme 2004 and workshop 2005. Cefas, Lowestoft, UK. 17-20 October, 2005. 
408 Clausen, L.W. 2006. Age estimation of herring from the North Sea, subdiv. IIIa, and the Baltic.

409 In Towards Accreditation and Certification of Age, Determination of Aquatic Resources

410 (TACADAR) 1 October 2002 to 31 October 2006.

411 Campana, S.E. 2001. Accuracy, precision and quality control in age determination, including a

412 review of the use and abuse of age validation methods. J. Fish Biol. 59: 197-242.

413 Campana, S.E. \& Thorrold, S.R. 2001. Otoliths, increments, and elements: keys to a

414 comprehensive understanding of fish populations? Can. J. Fish. Aquat. Sci. 58: 30-38.

415 Cohen, D.M., Inada, T., Iwamoto, T. \& Scialabba, N. 1991. FAO species catalogue vol. 10.

416 Gadiform fishes of the world. Order Gadiformes. An annotated and illustrated catalogue of cods,

417 hakes, grenadiers and other gadiform fishes known to date. FAO (Food and Agriculture

418 Organization of the United Nations) Fish. Syn. 125 (10): I-X, 1-442.

419 EU 2010. Commission Decision of 18 December 2009 adopting a multiannual Community

420 programme for the collection, management and use of data in the fisheries sector for the period

$4212011-2013$ (2010/93/EU), Official Journal of the European Union, 16.2.2010, L 41/8-71.

422 Flintegaard, H. 1980. Hvillingens (Merlangius merlangus) fødebiologi. Master's thesis.

423 Danmarks Fiskeri Undersøgelser, Denmark.

424 Gambell, R. \& Messtorff, J. 1964. Age determination in the whiting (Merlangius merlangus) by

425 means of the otoliths. J. Cons. Perma. int. Explor. Mer. 28 (3): 393-404.

426 Hislop, J.R.G. 1975. Breeding and growth of whiting, Merlangius merlangus, in captivity. J.

427 Con. 36: 199-27. 
Hüssy, K. 2010. Why is age determination of Baltic cod (Gadus morhua) so difficult? ICES J. Mar. Sci. 67: 1198-1205.

Hüssy, K. Hinrichsen, H.-H., Fey, D.P., Walther, Y. \& Velasco, A. 2010. The use of otolith microstructure to estimate age in adult Atlantic cod Gadus morhua. J. Fish Biol. 76: 1640-54.

Hüssy, K. Coad. J.O., Farrell, E.D., Clausen, L.W. \& Clarke, M.W. 2012. Age verification of boarfish (Capros aper) in the Northeast Atlantic. ICES J. Mar. Sci. 69: 34-40.

Krohn, M.M. \& Kerr, S.R. 1997. Declining weight-at-age in Northern cod and the potential importance of the early years and size-selective fishing mortality. NAFO Sci. Stud. 29: 43-50.

Morales-Nin, B., Torres, G.J., Lombarte, A. \& Recasens, L. 1998. Otolith growth and age estimation in the European hake. J. Fish Biol. 53: 1155-68.

Oeberst, R., Dickey-Collas, M., \& Nash, R.D.M. 2009. Mean daily growth of herring larvae in relation to temperature over a range of 5-20 degrees $\mathrm{C}$, based on weekly repeated cruises in the Greifswalder Bodden. ICES J. Mar. Sci. 66 (8): 1696-1701.

Pannella, G. 1974. Otolith growth patterns: an aid in age determination in temperate and tropical fishes. In Ageing of fish, pp. 28-39. Ed. By T.B. Bagenal. Unwin Bros, Surrey, UK.

Polat, N. \& Gümüs, A. 1996. Ageing of whiting (Merlangius merlangus euxinus, Nord., 1840) based on broken and burnt otolith. Fish. Res. 28: 231-36.

de Pontual, H., Groison, A.L., Piñeiro, C. \& Bertignac, M. 2006. Evidence of underestimation of European hake growth in the Bay of Biscay, and its relationship with bias in the agreed method of age estimation. ICES J. Mar. Sci. 63: 1674-81. 
448 Quiñonez-Velázquez, C. 1998. Age validation and growth of larval and juvenile haddock, 449 Melanogrammus aeglefinus, and Pollock, Pollachius virens, on the Scoatian Shelf. Fish. B$450 \quad$ NOAA 97: 306-19.

451 Reeves, S.A. 2003. A simulation study of the implications of age-reading errors for stock 452 assessment and management advice. ICES J. Mar. Sci. 60: 314-28.

453 Rehberg-Haas, S., Hammer, C., Hillgruber, N., Hüssy, K. \& Temming, A. 2012. Otolith

454 microstructure analysis to resolve seasonal patterns of hatching and settlement in western Baltic 455 cod. ICES J. Mar. Sci. 69 (8): 1347-56.

456 R Development Core Team. 2009. R: A Language and Environment for Statistical Computing. R 457 Foundation for Statistical Computing, Vienna. http://www.R-project.org

458 Rindorf, A., Jensen, H., and Schrum, C. 2008. Growth, temperature, and density relationships of 459 North Sea cod (Gadus morhua). Can. J. Fish. Aquat. Sci. 65: 456-470.

460 Smedstad, O.O. \& Holm, J.C. 1996. Validation of back-calculated formulae for cod otoliths. J. $461 \quad$ Fish Biol. 49: 976-85. 
464 Table 1 Whiting otolith growth. $\mathrm{D}_{\mathrm{i}}$ is the distance from the nucleus to the respective winter ring.

465 Mean $D_{i-1}$ is the distance between the $1^{\text {st }}$ and $2^{\text {nd }}$ winter ring (shown in the $2^{\text {nd }}$ winter ring row),

$4662^{\text {nd }}$ and $3^{\text {rd }}$ winter ring and so forth. All measurements are in $\mu \mathrm{m}$.

\begin{tabular}{|lcccc|}
\hline Winter ring & Mean D & Range of $D_{i}$ & Mean $D_{i-1}$ & Range of $D_{i-1}$ \\
Jumber & & & \\
1 & 1500 & $800-2100$ & & \\
2 & 2600 & $1800-3600$ & & \\
3 & 3900 & $2900-5200$ & 1180 & $700-1600$ \\
4 & 5000 & $3800-6400$ & 940 & $600-1400$ \\
5 & 6000 & $5200-6900$ & 750 & $450-850$ \\
\hline
\end{tabular}




\section{Figure captions}

469 Fig. 1 Sampling area. ICES subdivisions 22 and 24. The Femern Belt area is encircled.

470 Fig. 2 Length distribution for the 2009-2011 cohorts. The length distributions for the 2009-2011

471 cohorts caught in November 2011, January 2012 and May 2012. Estimated numbers are based on

472 the length proportions from a sample taken from each haul, i.e. the number in each length group $i$

473 for all hauls is calculated as $N_{i}=\sum S_{i, h}{ }_{V_{h}}$, where $S_{i, h}$ denotes the numbers of length group $i$ in

474 the sample drawn from the haul $h, W_{h}$ is the total weight of whiting in the haul $h$ and $V_{h}$ is the 475 weight of the sample drawn from haul $h$.

476 Fig. 3 Example of a whole, untreated Baltic Sea whiting otolith. The measurement axis is shown, $477 \quad \mathrm{D}=$ the distance from the nucleus to the $1^{\text {st }}$ annulus.

478 Fig. 4 Ageing of whole and ground otoliths. Ageing of otolith from a fish, length of $22 \mathrm{~cm}$, 479 caught in May 2012. Image of (a) whole otolith and (b) ground otolith. Nucleus as well as the 480 visual annuli are marked.

481 Fig. 5 Distance from nucleus to $1^{\text {st }}$ and $2^{\text {nd }}$ annulus as a function of fish length. (a) Distance from 482 the nucleus to the $1^{\text {st }}$ annulus $(\mu \mathrm{m})$ shown as a function of the fish length $(\mathrm{cm})$ and $(\mathrm{b})$ Distance 483 from the nucleus to the $2^{\text {nd }}$ annulus $(\mu \mathrm{m})$ shown as a function of the fish length $(\mathrm{cm})\left(\mathrm{NB}\right.$ : the $1^{\text {st }}$ 484 visual annulus of the whole otoliths is plotted as this in reality corresponds to the $2^{\text {nd }}$ annulus).

485 Whole otoliths are shown with black dots and ground otoliths with red triangles.

486 Fig. 6 Increment width as a function of the distance from the nucleus. Ground otolith from 1-year 487 old fish (length $18 \mathrm{~cm}$ ) caught in November 2011. (a) Microstructure profile showing the 488 increment widths as a function of the distance from the nucleus. (b) Increment widths of a 
489 section of the otolith where the translucent area corresponds to the $1^{\text {st }}$ annulus (7x magnification

$\left.490=0.32 \mu \mathrm{mpixel}^{-1}\right)$. (c) $\mathrm{D}_{\text {Ground }}$ shown with a straight line $(\approx 2000 \mu \mathrm{m})$.

491 Fig. 7 Otolith growth trajectories. The distances from the nucleus to $1^{\text {st }}, 2^{\text {nd }}, 3^{\text {rd }}$ and $4^{\text {th }}$ annulus

492 (based on ground otoliths) are shown as a function of the annulus number. The lines show the

493 growth curves for 22 age 3 fish and 10 age 4 fish. Each line corresponds to an individual fish.

494 Fig. 8 Percentage of otoliths with an opaque edge zone. Otoliths with an opaque edge shown as a

495 percentage of the total number of otoliths analyzed per month 
498 Fig. 1 Sampling area

499

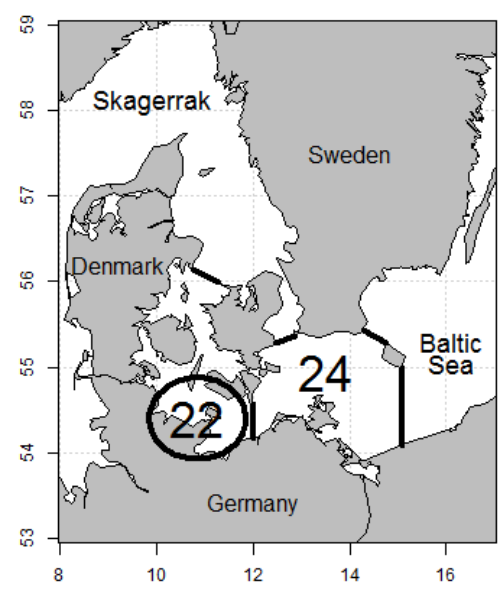

500

Fig. 2 Length distribution for the 2009-2011 cohorts
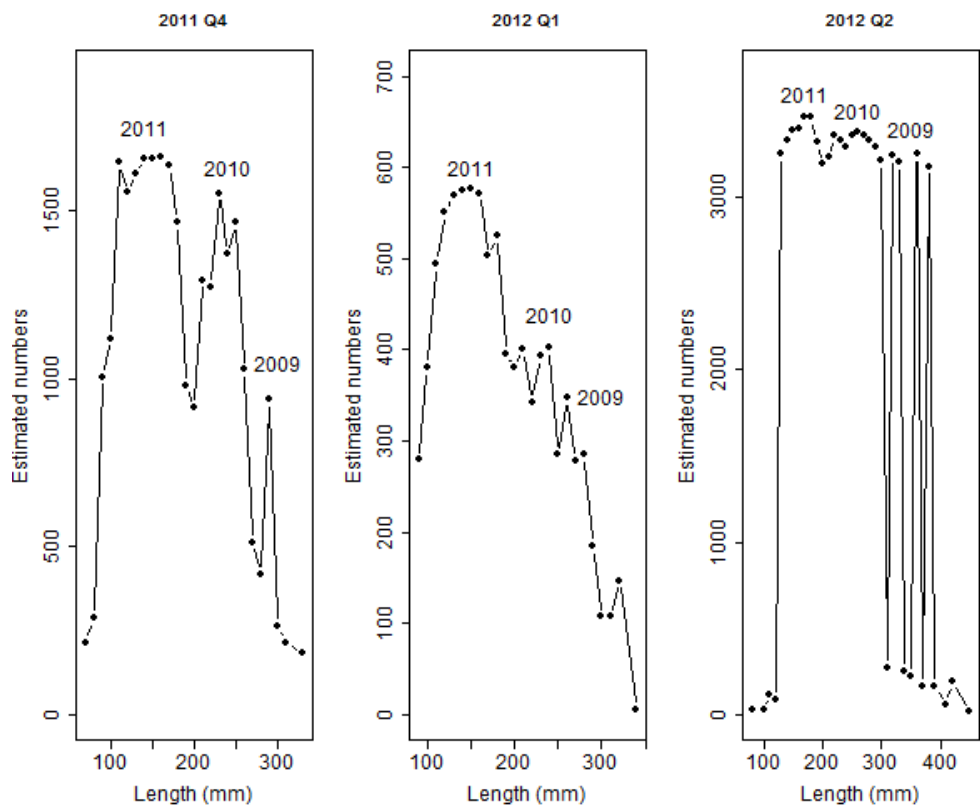

502 
503 Fig.3 Example of a whole, untreated Baltic Sea whiting otolith

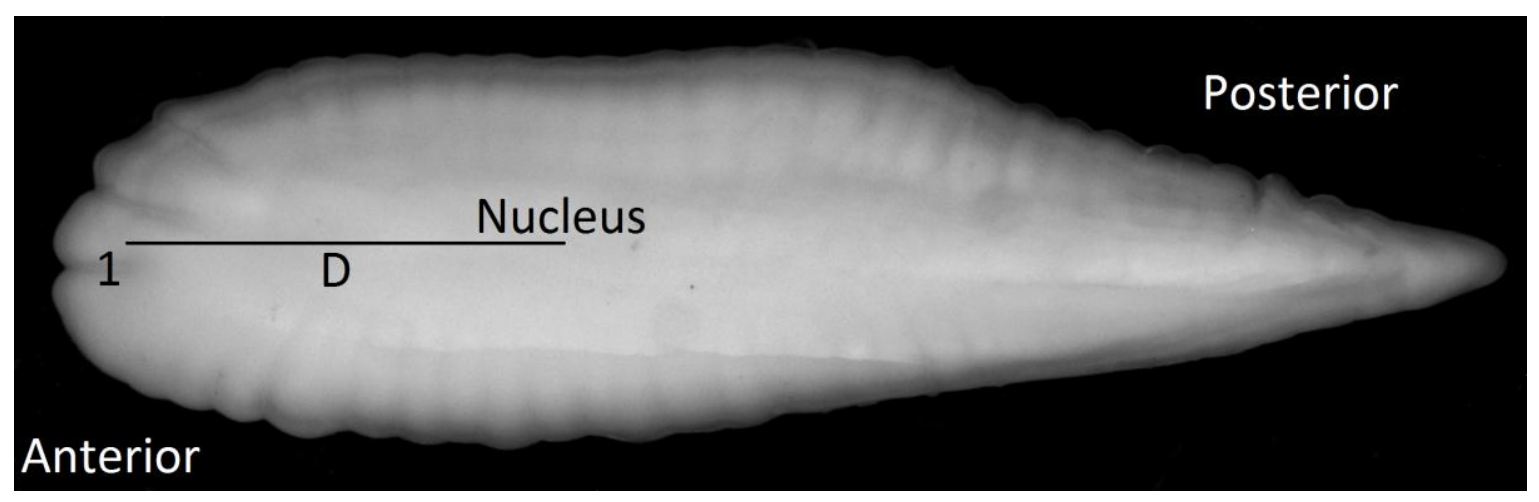

505 Fig. 4 Ageing of whole and ground otoliths
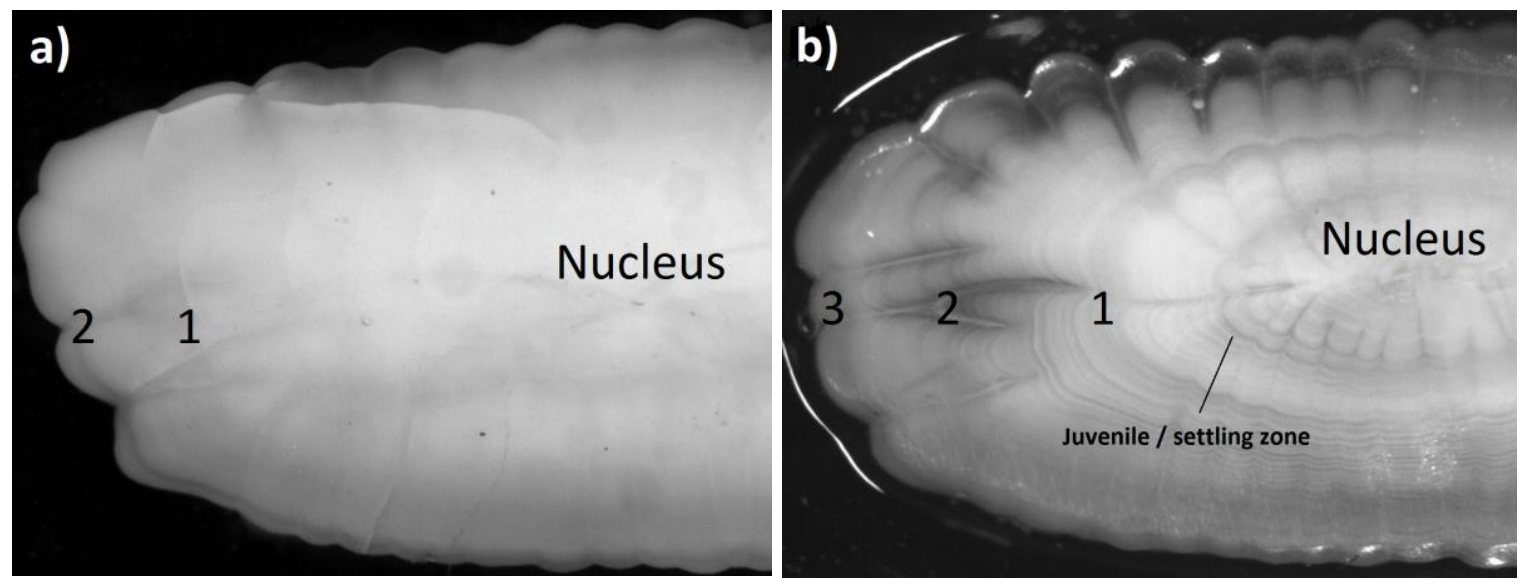

507 Fig. 5 Distance from nucleus to $1^{\text {st }}$ and $2^{\text {nd }}$ annulus as a function of fish length
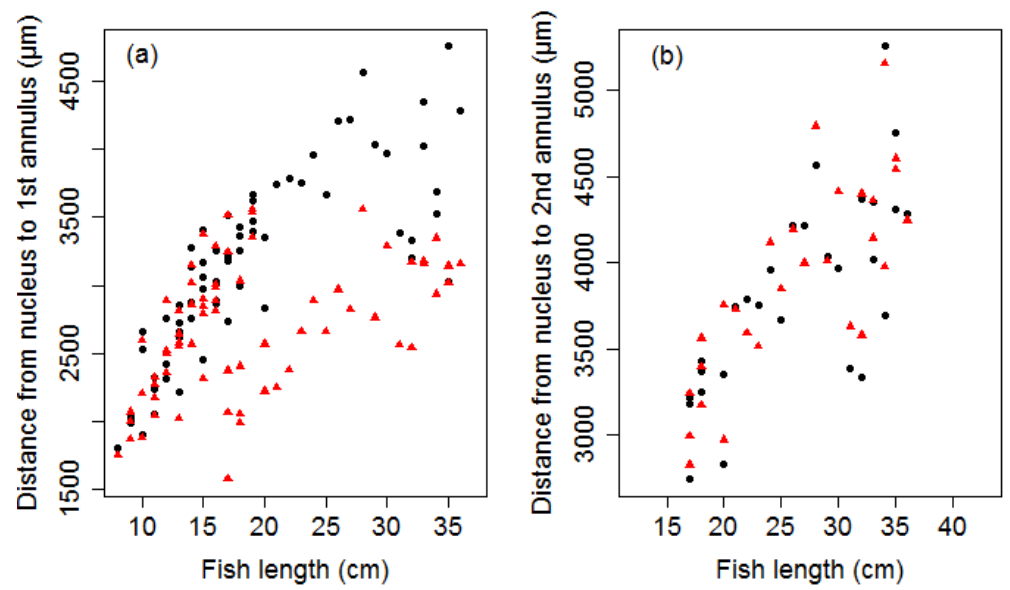
510 Fig. 6 Increment width as a function of the distance from the nucleus
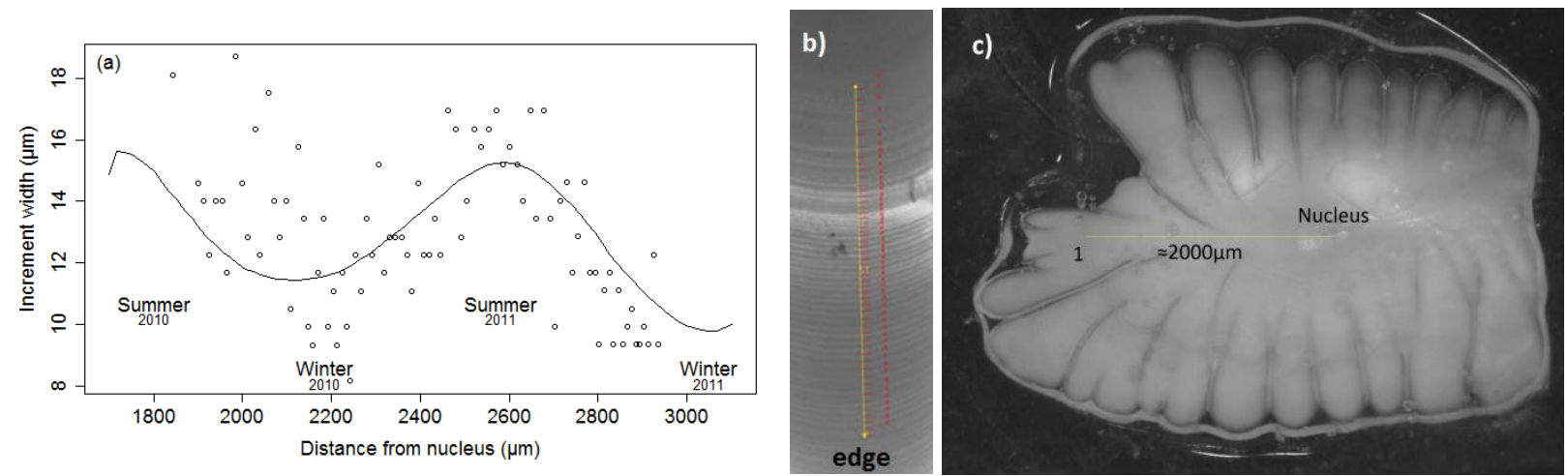

511

Fig. 7 Otolith growth trajectories

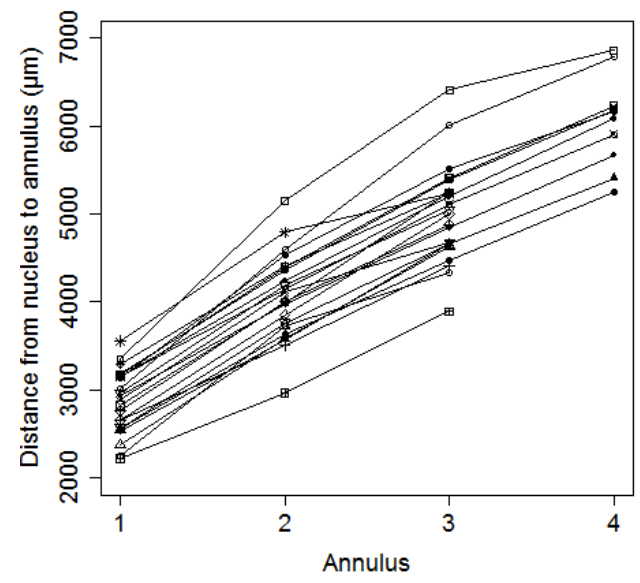

513

514 Fig. 8 Percentage of otoliths with an opaque edge zone

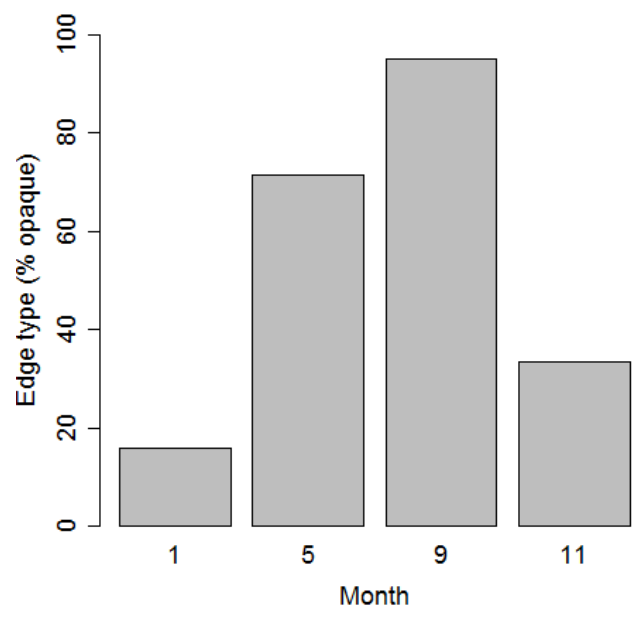

